\title{
Determination of Environmental Noise Contamination
}

\author{
O. GÜNAY*, O. YARAR AND M. SARIHAN \\ Istanbul Okan University, Vocational School of Health Services, Istanbul,Turkey
}

\begin{abstract}
Noise pollution - one of the major environmental problems, affects people both physiologically and psychologically. Noise measurements must be carried out regularly to overcome the noise problem. The study in this paper was conducted to determine the noise level in different parts of an education and research hospital in Istanbul. Noise levels were measured at the main entrance, pediatric department, emergency room entrance, audiology clinic, nuclear medicine cardiology clinic, eye clinic, and emergency service corridor of the hospital. Measurements were taken on Monday, Tuesday, Wednesday, Thursday, and Friday, every hour from 08:00 in the morning to 17:00 in the afternoon. As a result, average noise levels were found between $52 \mathrm{~dB}$ and $57 \mathrm{~dB}$ in different parts of the hospital. The results were compared with similar studies and recommendation in WHO guidelines.
\end{abstract}

DOI: 10.12693/APhysPolA.137.574

PACS/topics: noise, environmental pollution, hospital management

\section{Introduction}

There are many environmental problems that affect people [1]. Some of these environmental problems are soil pollution, air pollution, water pollution, radiation pollution, and noise pollution [2-5]. Several studies have been conducted to determine the levels of these environmental problems [6-7].

Noise can be defined as disturbing sounds to the human ears. The intensity of noise is measured in decibels $(\mathrm{dB})$ and is referred as a function of the sound pressure. The level of environmental noise increased after the industrial revolution, in particular, with a significant increase in mechanization. In all environments where people live, such as schools, workplaces, homes, and hospitals, there is a certain level of noise.

Development of technology caused that there appeared the number of electronic devices used in the hospital. Noise from these devices is damaging for both the patients and the employees. The noise sources in hospitals are very diverse. There are two effective factors that influence this noise level. One of them are all sources of hospital noise. The second is the environmental physiology of the hospital. The major noise sources in the hospital are personnel voices, alarms, announcements, telephone rings, paging systems, pneumatic tubes, patient voices, and cars (emergency cars, washing cars, stretchers, and other material carriers). Environmental physiology, in turn, includes the surfaces surrounding the hospital, walls, floors, and ceilings. Acoustic conditions in these environments increase the noise level as well.

For the patients exposed to noise in hospitals, the resulting problems are, e.g., an increased heart rate, metabolism and oxygen consumption, anxiety, and pain perception, increased corticosteroid release, and

*corresponding author; e-mail: osman.gunay@okan.edu.tr decreased respiratory function [8-10]. Other important problems related to noise in patients are sleep disorder and stress and intensive care psychosis [11]. In addition, anxiety, irritability, trial disturbance, changes in perception, and concentration difficulties are observed in the personnel exposed to noise. This may lead to impaired mental abilities and a decrease in job performance [12]. One of the negative effects of noise in hospitals is that they cause splits and errors in medical treatment processes.

A quiet, calm, and pleasant environment in hospitals can benefit both health personnel and patients. Health personnel working in a quiet environment will be physiologically and psychologically healthier. Thus, they will contribute to faster recovery of patients. Therefore, determining the noise level in hospitals is very important for both sides. In this study, the aim was to determine noise levels in different departments of a university hospital.

\section{Materials and methods}

This study was carried out in Istanbul Okan University Research and Application Hospital which was opened in 2014. It was established on a $50000 \mathrm{~m}^{2}$ closed area. It serves as a fully equipped general hospital with more than 500 employees and lecturers, 250 bed capacity, 10 operating rooms, intensive care unit with 47 beds, and technological infrastructure. The distance of the hospital to the main road is $200 \mathrm{~m}$ (Fig. 1).

Noise levels were measured at the main entrance, pediatric department, emergency room entrance, audiology clinic, nuclear medicine cardiology clinic, eye clinic, and emergency service corridor of the hospital. Measurements were performed on Monday, Tuesday, Wednesday, Thursday, and Friday, taken in every hour from 08:00 in the morning to 17:00 in the afternoon. 


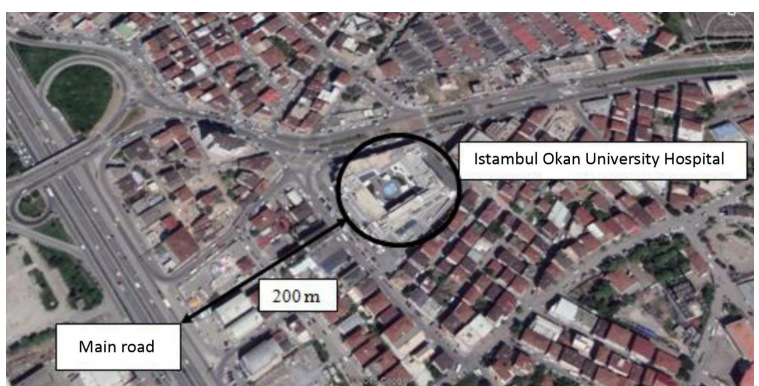

Fig. 1. Studying Area (Istanbul Okan University Hospital).

We used the device with the CEM Mark, DT-805 Model. The integrated mean was obtained with

$$
L A_{e q}=10 \log _{10}\left(\frac{1}{n_{j}} \sum_{i=1}^{n} 10^{L_{e} q_{i} j / 10}\right),
$$

where $i$ corresponds to observation of the A-weighted equivalent continuous level reported in the hourly interval $j$, and $n$ is the total number of $i$ observations in the $j$ hour [7].

\section{Results and discussion}

On Monday, the lowest noise level was found to be $53.04 \mathrm{~dB}$ at 17:00, while the highest noise level was $66.12 \mathrm{~dB}$ at 10:00. The average noise level in main entrance of the hospital was equal $60.12 \mathrm{~dB}$. On Tuesday, the lowest noise level was found to be $52.02 \mathrm{~dB}$ at 17:00, while the highest noise level was $66.91 \mathrm{~dB}$ at 12:00, while and the average noise level was $60.29 \mathrm{~dB}$. On Wednesday, the lowest noise level was found to be $54.78 \mathrm{~dB}$ at 16:00, while the highest noise level of $62.15 \mathrm{~dB}$ was at 08:00. The average noise level was 58.61 dB. On Thursday, the lowest noise level was found to be $53.58 \mathrm{~dB}$ at 14:00, while the highest noise level of $63.52 \mathrm{~dB}$ was at 08:00, and the average noise level was $57.70 \mathrm{~dB}$. On Friday, the lowest noise level was found to be $52.67 \mathrm{~dB}$ at 17:00, while the highest noise level was $63.56 \mathrm{~dB}$ at 08:00. The average noise level in main entrance of the hospital was $58.28 \mathrm{~dB}$ (Fig. 2).

In case of pediatric department, the lowest noise level on Monday was found to be $53.78 \mathrm{~dB}$ at 16:00, while the highest noise level of $61.15 \mathrm{~dB}$ was at 08:00. The average noise level was $57.61 \mathrm{~dB}$. On Tuesday, the lowest noise level was found to be $51.92 \mathrm{~dB}$ at 17:00, while the highest noise level of $64.41 \mathrm{~dB}$ was at 10:00, and thus the average noise value was $58.00 \mathrm{~dB}$. On Wednesday, the lowest noise level was found to be $49.52 \mathrm{~dB}$ at 17:00, while the highest noise level equal $64.41 \mathrm{~dB}$ was at 12:00. The average noise level was $57.79 \mathrm{~dB}$. On Thursday, the lowest noise level was found to be $51.00 \mathrm{~dB}$ at 17:00, while the highest noise level of $64.12 \mathrm{~dB}$ was at 10:00, and the average noise level was $58.12 \mathrm{~dB}$. On Friday, the lowest noise level was found to be $50.92 \mathrm{~dB}$ at 17:00, while the highest noise level of $58.91 \mathrm{~dB}$ was at 09:00. The average noise level was $55.38 \mathrm{~dB}$ (Fig. 3).

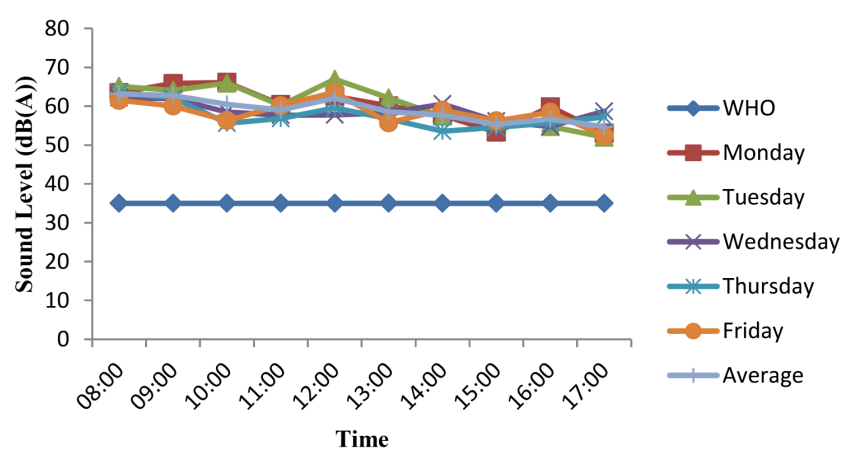

Fig. 2. The noise level at different days and hours in main entrance of the hospital.

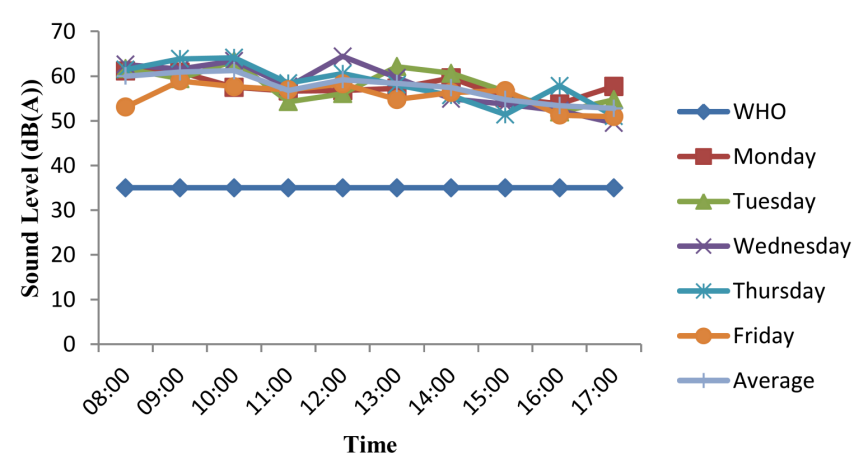

Fig. 3. The noise level at different days and hours in pediatrics department.

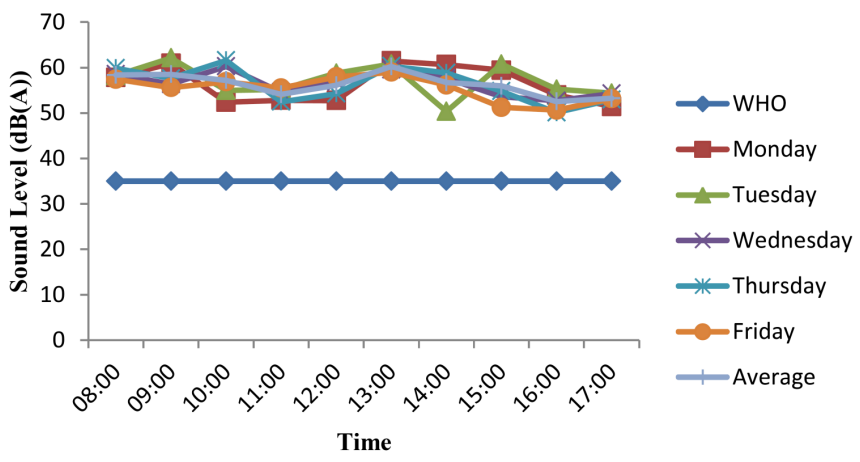

Fig. 4. The noise level at different days and hours in emergency room entrance.

In emergency room entrance, the lowest noise level on Monday was found to be $51.45 \mathrm{~dB}$ at 17:00, while the highest noise level was $61.45 \mathrm{~dB}$ at 13:00 and the average noise level was $56.37 \mathrm{~dB}$. On Tuesday, the lowest noise level was found to be $50.35 \mathrm{~dB}$ at 14:00, while the highest noise level was $62.11 \mathrm{~dB}$ at 09:00 and the average noise level was $56.93 \mathrm{~dB}$. On Wednesday, the lowest noise level was found to be $52.69 \mathrm{~dB}$ at 16:00, while the highest noise level was $60.25 \mathrm{~dB}$ at 10:00 and the average noise level was $56.43 \mathrm{~dB}$. On Thursday, the lowest noise level was found to be $50.12 \mathrm{~dB}$ at 16:00, while 


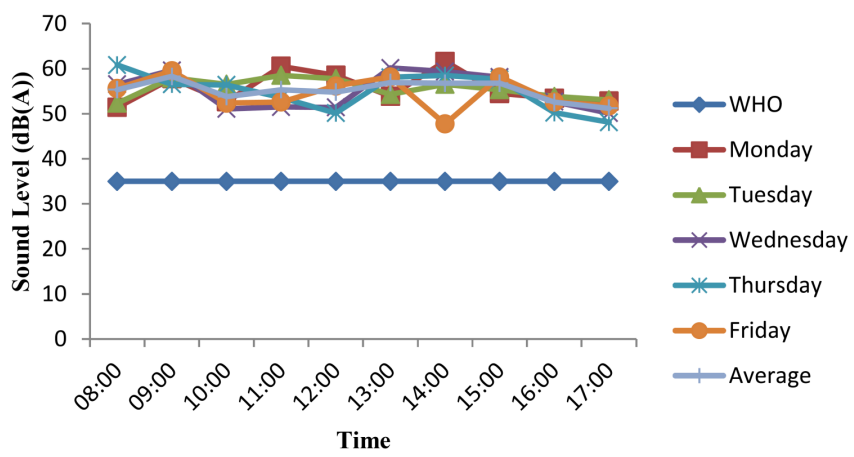

Fig. 5. The noise level at different days and hours in audiology clinic.

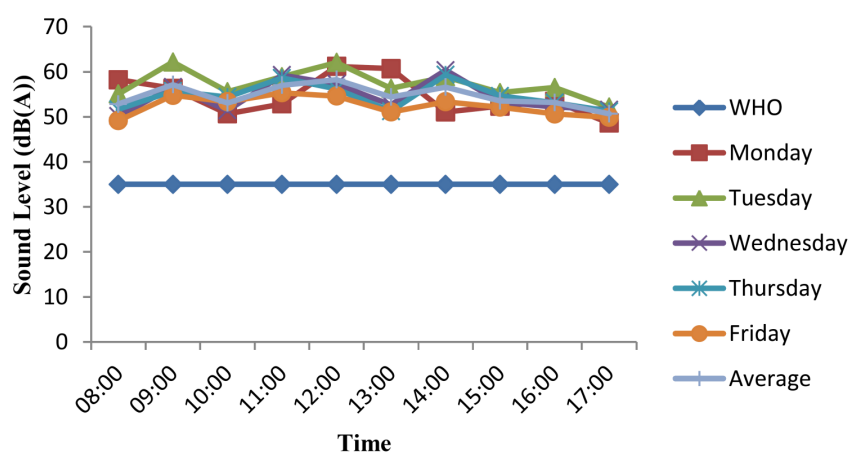

Fig. 6. Noise level at different days and hours in nuclear medicine.

the highest noise level was $61.57 \mathrm{~dB}$ at 10:00 and the average noise level was $56.20 \mathrm{~dB}$. On Friday, the lowest noise level was found to be $50.56 \mathrm{~dB}$ at 16:00, while the highest noise level was $59.00 \mathrm{~dB}$ at 13:00. The average noise level in emergency room entrance was $55.26 \mathrm{~dB}$ (Fig. 4).

In audiology clinic, the lowest noise level on Monday was found to be $51.39 \mathrm{~dB}$ at 08:00, while the highest noise level was $61.61 \mathrm{~dB}$ at 14:00. The average noise level was $55.84 \mathrm{~dB}$. On Tuesday, the lowest noise level was found to be $52.33 \mathrm{~dB}$ at 08:00, while the highest noise level was $58.53 \mathrm{~dB}$ at 11:00, and the average noise level was $55.58 \mathrm{~dB}$. On Wednesday, the lowest noise level was found to be $50.15 \mathrm{~dB}$ at 17:00, while the highest noise level was $60.15 \mathrm{~dB}$ at 13:00 and the average noise level was $55.07 \mathrm{~dB}$. On Thursday, the lowest noise level was found to be $48.12 \mathrm{~dB}$ at 17:00, while the highest noise level was $60.83 \mathrm{~dB}$ at 08:00 and the average noise level was $54.91 \mathrm{~dB}$. On Friday, the lowest noise level was found to be $47.75 \mathrm{~dB}$ at 14:00, while the highest noise level of 59.51 dB was at 09:00. The average noise level in audiology clinic was $54.33 \mathrm{~dB}$ (Fig. 5).

On Monday, the lowest noise level was found to be $48.62 \mathrm{~dB}$ at 17:00, while the highest noise level was $61.18 \mathrm{~dB}$ at 12:00 and the average noise level was $54.60 \mathrm{~dB}$ in nuclear medicine. On Tuesday, the lowest noise level was found to be $52.12 \mathrm{~dB}$ at 17:00, while the highest noise level was $62.16 \mathrm{~dB}$ at 12:00 and the av-

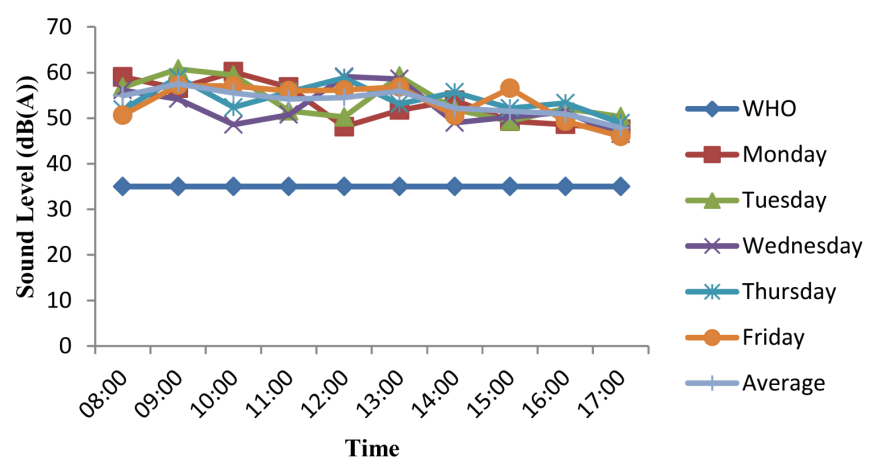

Fig. 7. The noise level at different days and hours in cardiology clinic.

erage noise level was $57.26 \mathrm{~dB}$. On Wednesday, the lowest noise level was found to be $50.13 \mathrm{~dB}$ at 08:00, while the highest noise level was $60.35 \mathrm{~dB}$ at 14:00 and the average noise level was $54.58 \mathrm{~dB}$. On Thursday, the lowest noise level was found to be $51.22 \mathrm{~dB}$ at 17:00, while the highest noise level was $59.33 \mathrm{~dB}$ at 14:00, and the average noise level was $54.72 \mathrm{~dB}$. On Friday, the lowest noise level was found to be $49.13 \mathrm{~dB}$ at 08:00, while the highest noise level of $55.33 \mathrm{~dB}$ was at 14:00. The average noise level in nuclear medicine was $52.38 \mathrm{~dB}$ (Fig. 6).

On Monday, the lowest noise level was found to be $47.59 \mathrm{~dB}$ at 17:00. The highest noise level was $60.11 \mathrm{~dB}$ at 10:00 and the average noise level was $53.28 \mathrm{~dB}$ in cardiology clinic. On Tuesday, the lowest noise level was found to be $49.29 \mathrm{~dB}$ at 15:00. The highest noise level was $60.76 \mathrm{~dB}$ at 09:00 and the average noise level was $54.30 \mathrm{~dB}$. On Wednesday, the lowest noise level was found to be $46.52 \mathrm{~dB}$ at 17:00, while the highest noise level of $59.08 \mathrm{~dB}$ was at 12:00 and the average noise level was $52.50 \mathrm{~dB}$. On Thursday, the lowest noise level was found to be $48.92 \mathrm{~dB}$ at 17:00. The highest noise level was $58.93 \mathrm{~dB}$ at 09:00. The average noise level was $54.06 \mathrm{~dB}$. On Friday, the lowest noise level was found to be $45.96 \mathrm{~dB}$ at 17:00, while the highest noise level of $57.18 \mathrm{~dB}$ was at 09:00. The average noise level in cardiology clinic was $53.28 \mathrm{~dB}$ (Fig. 7).

On Monday, the lowest noise level was found to be $48.78 \mathrm{~dB}$ at 17:00, while the highest noise level was $57.92 \mathrm{~dB}$ at 14:00 and the average noise level was $52.36 \mathrm{~dB}$ in eye clinic. On Tuesday, the lowest noise level was found to be $49.68 \mathrm{~dB}$ at 14:00, while the highest noise level was $58.33 \mathrm{~dB}$ at 10:00 and the average noise level was $53.48 \mathrm{~dB}$. On Wednesday, the lowest noise level was found to be $46.39 \mathrm{~dB}$ at 17:00, while the highest noise level was 58.91 $\mathrm{dB}$ at 10:00 and the average noise level was $52.08 \mathrm{~dB}$. On Thursday, the lowest noise level was found to be $47.69 \mathrm{~dB}$ at 15:00, while the highest noise level was 59.16 dB at 09:00 and the average noise level was $52.70 \mathrm{~dB}$. On Friday, the lowest noise level was found to be $46.95 \mathrm{~dB}$ at 16:00, while the highest noise level was $59.89 \mathrm{~dB}$ at 10:00. The average noise level in eye clinic was $52.96 \mathrm{~dB}$ (Fig. 8). 


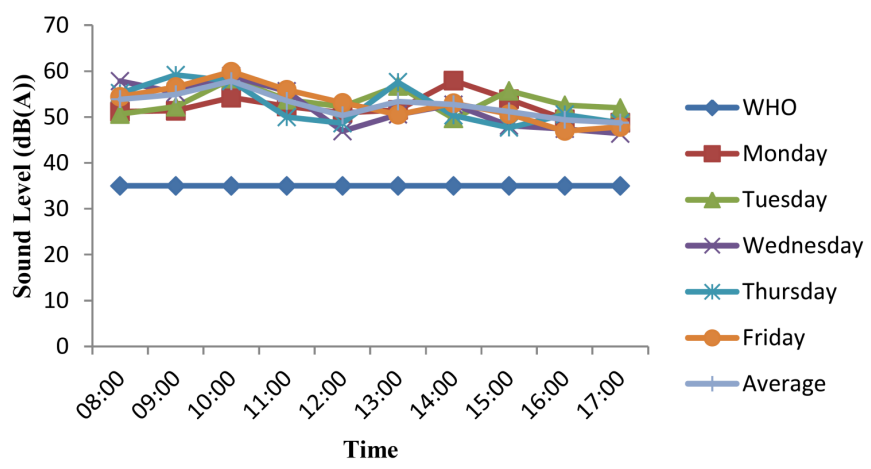

Fig. 8. The noise level at different days and hours in eye clinic.

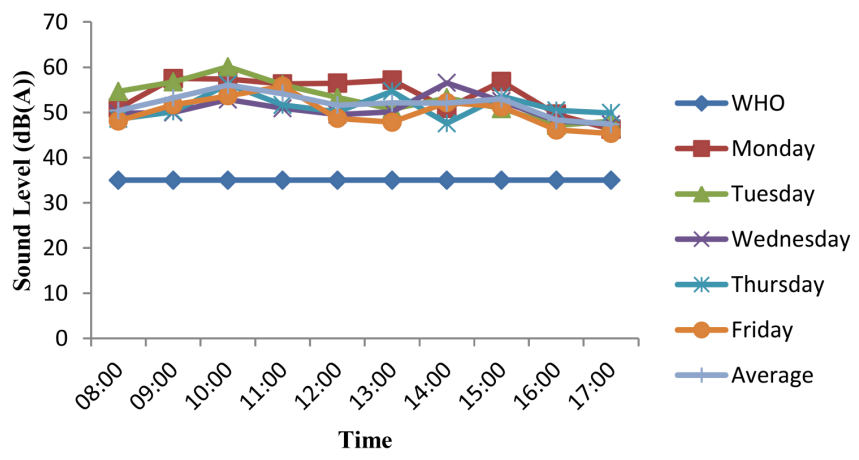

Fig. 9. The noise level at different days and hours in emergency service corridor.

On Monday, the lowest noise level was found to be $46.26 \mathrm{~dB}$ at 17:00, while the highest noise level was $57.48 \mathrm{~dB}$ at 09:00 and the average noise level was $53.58 \mathrm{~dB}$ in eye clinic. On Tuesday, the lowest noise level was found to be $47.15 \mathrm{~dB}$ at 16:00, while the highest noise level was $60.09 \mathrm{~dB}$ at 10:00 and the average noise level was $53.16 \mathrm{~dB}$. On Wednesday, the lowest noise level was found to be $47.38 \mathrm{~dB}$ at 17:00, while the highest noise level was $56.52 \mathrm{~dB}$ at 14:00 and the average noise level was $50.96 \mathrm{~dB}$. On Thursday, the lowest noise level was found to be $47.58 \mathrm{~dB}$ at 14:00, while the highest noise level was $56.23 \mathrm{~dB}$ at 10:00 and the average noise level was $51.38 \mathrm{~dB}$. On Friday, the lowest noise level was found to be $45.34 \mathrm{~dB}$ at 17:00, while the highest noise level was $55.75 \mathrm{~dB}$ at 11:00. The average noise level in emergency service corridor was $50.13 \mathrm{~dB}$ (Fig. 9).

As a result of the measurements made at Istanbul Okan University hospital, the highest noise level (59.02 dB) was determined at the main entrance of the hospital, while the lowest $(51.80 \mathrm{~dB})$ was in the emergency service corridor. The noise levels in the pediatrics department, emergency room entrance, audiology clinic, nuclear, medicine, cardiology clinic, and eye clinic are $57.39 \mathrm{~dB}, 56.31 \mathrm{~dB}, 55.10 \mathrm{~dB}, 54.63 \mathrm{~dB}, 53.36 \mathrm{~dB}$, and $52.70 \mathrm{~dB}$, respectively (Fig. 10).

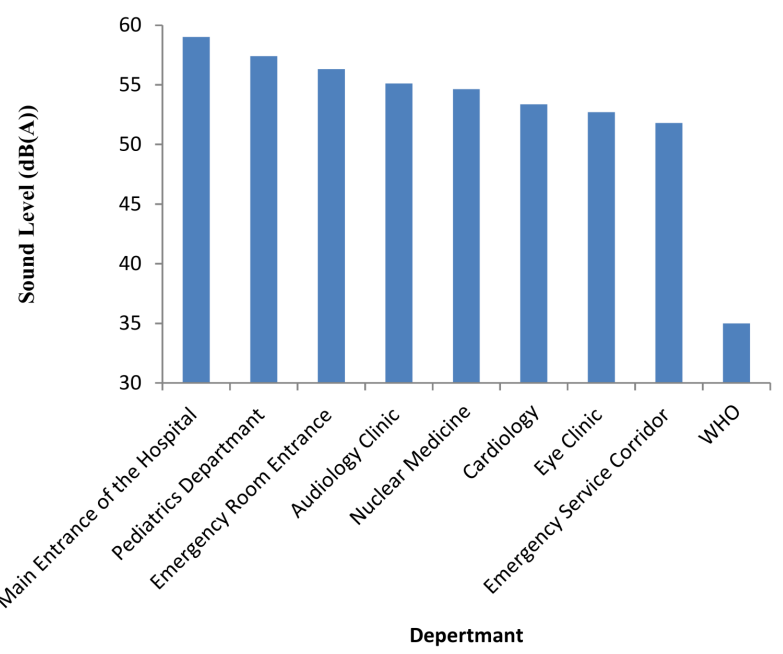

Fig. 10. The noise level at different department in hospital.

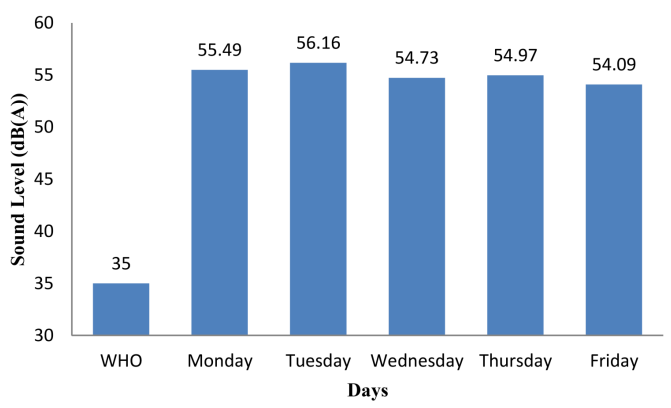

Fig. 11. The noise level at different days in hospital.

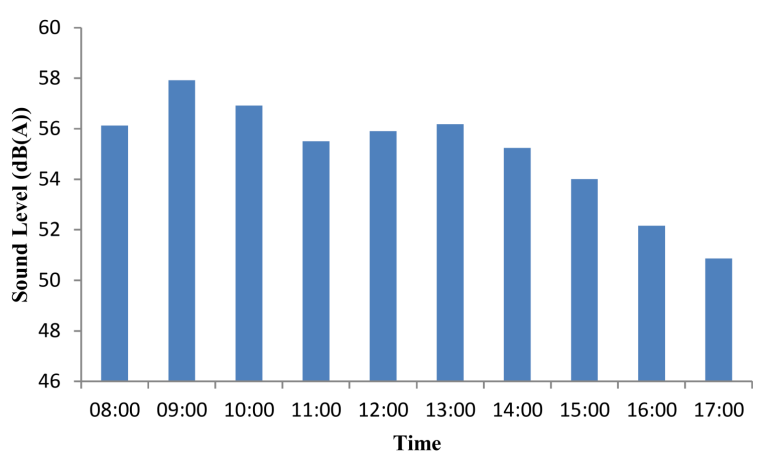

Fig. 12. The noise level at different hours in hospital.

When the noise measurement results of all departments in the hospital are evaluated, the noise level is found to be highest on Tuesday. The average noise levels calculated for Monday, Tuesday, Wednesday, Thursday, and Friday are $55.49 \mathrm{~dB}, 56.16 \mathrm{~dB}, 54.73 \mathrm{db}, 54.97 \mathrm{~dB}$, and $54.09 \mathrm{~dB}$, respectively (Fig. 11).

Based on the results of noise measurements at different working hours, it was found that they are at different levels. The highest noise level $(57.91 \mathrm{~dB})$ was found at $9 \mathrm{am}$. The minimum noise level $(50.86 \mathrm{~dB})$ was found at $5 \mathrm{pm}$ (Fig. 12). 
Long-term exposure to noise pollution can cause many physical and psychological health problems. Some of the health problems associated with hearing are presbycusis and sensorineural hearing [13]. The likelihood of hearing loss is $85 \%$ for people who are exposed to a noise level of approximately $85 \mathrm{~dB}$ for 8 years per day for 40 years[14]. The non-auditory effects of noise pollution on human health are stress and sleep disturbance. Other effects of exposure to high levels of noise may include increased blood pressure, nausea, headache, and anxiety disorder [15].

Several studies have been conducted to determine the noise level in hospitals. In 2013, noise level measurements were made in 5 different hospitals in Istanbul, and the following results were obtained $70.28 \mathrm{~dB}$, $71.57 \mathrm{~dB}, 74.42 \mathrm{~dB}, 70.42 \mathrm{~dB}$, and $67.14 \mathrm{~dB}$ [16]. Study in 2013 conducted 3 different departments of a training and research hospital in Istanbul and the average noise levels were reported as $75 \mathrm{~dB}, 65 \mathrm{~dB}$, and $65 \mathrm{~dB}$ [17]. In 2018, Yarar et al. measured noise levels at different departments in Istanbul Zeynep Kamil Hospital. The result of the study were noise level values between $65 \mathrm{~dB}$ and $74 \mathrm{~dB}$ [17]. In 2005, sound levels were measured at five different departments at Johns Hopkins Hospital in the USA. The noise level measurements performed in many units including the patient room, nurse stations and corridors were found to be $50-60 \mathrm{~dB}$ on average, and there were quite a few differences between the units [18]. In 2005, Tijunelis et al. investigated the noise levels in the emergency department. It was concluded that the xcessivee noise level was in the emergency room [19]. In 2008, Akansel and Kaymakci investigated the effects of noise in intensive care units, and they found higher values of noise levels than those recommended [20]. In 2018, the daytime noise level in public hospitals was between 64.3 and $73.8 \mathrm{~dB}$, while in private hospitals it ranged from 57.3 to $66.6 \mathrm{~dB}$ [21]. In case of studies in 3 different hospitals the noise level were found to vary between 54.3 and $62.6 \mathrm{~dB}[22]$.

In this paper, the noise level values were obtained for different departments in hospital, and they were estimated between $52 \mathrm{~dB}$ and $57 \mathrm{~dB}$. Our result was similar to the noise level measurements by Philbin and Gray, but lower in comparison to other measurements conducted in hospitals. The noise levels in our study are lower than the level of $85-90 \mathrm{~dB}$ which may cause hearing impairment. However, it is higher than recommended noise levels $(35 \mathrm{~dB})$ in WHO guidelines.

\section{Conclusion}

The level of noise in hospitals affects health personnel and patients. Therefore, noise level has to be measured regularly. In this study, noise levels were measured in different parts of a university hospital in Istanbul. Measurements were made each day from Monday to Friday, from 8 am to $5 \mathrm{pm}$.

The results were compared with similar studies and recommendation by WHO guidelines. As a result of this study, average noise levels in different parts of the hospital were found between $52 \mathrm{~dB}$ and $57 \mathrm{~dB}$. These noise levels were observed to be lower than in similar studies, but higher than the noise level recommended by the WHO. In fact, also in other studies the noise level was higher than the noise level recommended by WHO. Therefore, serious steps are needed to reduce hospital noise. In this way the productivity of healthcare professionals will increase, and patients will recover faster.

\section{Acknowledgments}

The authors wish to thank all who assisted in conducting this work.

\section{References}

[1] H. Palac1, O. Günay, O. Yarar O., Europ. J. Sci. Tech. 14, 249 (2018).

[2] O. Günay O, M.M. Saç, M. Içhedef, C. Taşköprü, Int. J. Env. Sci. Tech. 16, 5050 (2019).

[3] U. Kara, A. Kaya, H.O. Tekin, I. Akkurt, Act. Phys. Pol. A 132, 1126 (2017).

[4] S. Aközcan, Tox. Environ. Chem. 96, 379 (2014).

[5] S. Seçkiner, I. Akkurt, K. Günoglu, Acta Phys. Pol. A 132, 1095 (2017).

[6] O. Günay, E. Abamor, Inter. J. Environ. Sci. and Tech. 16, 5177 (2019).

[7] A.G. Galindo, Y.C. Caicedo, A.M. Vélez-Pereira, Med. Intens. 40, 403 (2016).

[8] S.M. Hsu, W.J. Ko, W.C. Liao, et al., Clinics. 65, 985 (2010).

[9] N. Lawson, K. Thompson, G. Saunders, et al., Am. J. Crit. Ca. 19, e88 (2010).

[10] I.N. Cabrera, M.H. Lee, Prev. Med. 30, 339 (2000).

[11] L. Goines, L. Hagler, South Med. J. 100, 287 (2007).

[12] D.B. Choiniere, Nurs. Admin. Quarter. 34, 327 (2010).

[13] P.M. Rabinowitz, Am. Famil. Phys. 61, 2759 (2000).

[14] F. Godlee, F Noise, Brit. Med. Journ. 304, 110 (1992).

[15] S.A. Stansfeld, M.P. Matheson, Brit. Med. Bull. 68, 243 (2003).

[16] E. Gültekin, Ö.N. Develioğlu, M. Yener et al., Turk. Arch. Otolar. 51, 101 (2013).

[17] O. Yarar, E. Temizsoy, O. Günay, Int. J. Env. Sci. Tech. 16, 5107 (2019).

[18] M.K. Philbin, L. Gray, J. Perinatol. 22(6), 455 (2002).

[19] M.A. Tijunelis, E. Fitzsullivan, S.O. Ame, J. Emerg. Med. 23, 332 (2005).

[20] N. Akansel, Ş. Kaymakçi, J. Clin. Nurs. 17, 1581 (2008).

[21] M. Baqar, M. Arslan, S.A. Abbasi, et al., Arch. Envir. Occup. Health 73, 367 (2018).

[22] M. Esmaeilzadeh, F. Sepahi, Z. Dashab, et al., Arch. Envir. Occup. Health 2, 169 (2018). 